\title{
Study on Various Compositions of Polyvinyl Alcohol and Starch Blends by Cross-Linking with Glyoxal
}

\author{
Ravindra V. Gadhave*, Prakash A. Mahanwar, Pradeep T. Gadekar \\ Department of Polymer and Surface Engineering, Institute of Chemical Technology, Mumbai, India \\ Email: *ravi.gadhave3@gmail.com
}

How to cite this paper: Gadhave, R.V., Mahanwar, P.A. and Gadekar, P.T. (2019) Study on Various Compositions of Polyvinyl Alcohol and Starch Blends by Cross-Linking with Glyoxal. Open Journal of Polymer Chemistry, 9, 76-85. https://doi.org/10.4236/ojpchem.2019.94007

Received: August 31, 2019

Accepted: October 14, 2019

Published: October 17, 2019

Copyright $\odot 2019$ by author(s) and Scientific Research Publishing Inc. This work is licensed under the Creative Commons Attribution International License (CC BY 4.0). http://creativecommons.org/licenses/by/4.0/

\begin{abstract}
The aim of this study is to analyze the various compositions of polyvinyl alcohol (PVA) and starch blends. The blends have been cross-linked with glyoxal to enhance its properties. The hydroxyl groups of PVA and starch react with glyoxal via formation of acetal bonds; hence crosslinking could take place. The cross-linking of glyoxal is observed in various analytical methods such as DSC and FTIR. The cross-linked blends showed better thermal and mechanical properties. Viscosity, tensile shear strength, pencil hardness and ultimate stress were evaluated to estimate the changes due to cross-linking. It was observed that the cross-linking is directly proportional to starch, since the starch hydroxyl groups are easily accessible for reacting. The cross-linked blend showed better cohesion between its chains, thereby increasing glass transition temperature. It was reflected in the subsequent increase in tensile strength properties.
\end{abstract}

\section{Keywords}

Starch, Polyvinyl Alcohol, Cross-Linking, Glyoxal, Mechanical Testing

\section{Introduction}

Starch is a relatively inexpensive and renewable product that can be obtained from multiple plant sources and that has been extensively used as wet end additive, coating binder, sizing agent, adhesive, and textile size [1] [2]. However, its bonding capacity is not strong enough to glue wood [3] [4] [5] [6] [7]. A few studies have been conducted on the potential of utilizing starch as wood adhesive. Recent studies have focused on formaldehyde-free wood adhesives, which are obtained through the reaction between a cross-linker and a blend of starch with other polymers, such as starch/polyvinyl alcohol [8], starch/tannin [9] [10] 
[11] and starch/isocyanates [12]. However, such wood adhesives cannot be used at room temperature because the required curing temperature is usually over $100^{\circ} \mathrm{C}[13]$. Many efforts have been exerted to develop starch-based polymers as alternatives of petroleum-based polymers [14] [15] [16].

Polyvinyl alcohol (PVA) is water soluble polymers, strong, durable and biodegradable. It possesses high crystalline structure [17]. Physical and chemical properties of PVA depend on the synthetics condition and degree of hydrolysis of the polymer [18] [19] [20] [21] [22]. To improve the properties, researchers have blended starch with other biodegradable polymers such as methyl cellulose and hydroxyl propylmethyl cellulose, polyhydroxyalkanoates poly lactic acid (PLA) and PVA. PVA contains secondary hydroxyl group that easily forms hydrogen bonds with starch. There is a wide variety of crosslinking agents for PVA, such as maleic acid, formaldehyde, and glyoxal [23].

PVA crosslinked with dialdehydes is one of the most commonly used techniques. It is well known that hydroxyl groups from PVA react with aldehydes via formation of acetal bonds. When dialdehyde is used, such as glyoxal or glyoxal, crosslinking reactions of PVA can be conducted under mild conditions [24] [25] [26]. Dialdehydes are the multifunctional reagents that cross-link starch by reacting with the hydroxyl groups of starch and intro-duce intermolecular bridges between the polysaccharides chains.

In this paper, the effects of various factors such as increasing starch content, increasing amount of glyoxal, on the performance properties like tensile strength, pencil hardness and thermal properties were studied.

\section{Experimental}

\subsection{Materials}

PVA (containing $86.5 \%$ to $89 \%$ degree of hydrolysis) were obtained from Kuraray Cooperative Limited, India. Maize starch containing 25\% - 30\% of amylose content was obtained from Sanstar Ltd. Glyoxal ( $40 \%$ content in water) was purchased from Sigma-Aldrich. Deionized water was used as the solvent in all experiments. Maize starch was dried to remove moisture.

\subsection{Preparation Method}

First, Maize starch and PVA blends were mixed in water and poured into a kettle. Second, the kettle was closed and was sealed to make it air tight. Third, the seal tight kettle was heated to $60^{\circ} \mathrm{C}$ temperature while mixing the sample at 175 $\mathrm{rpm}$. The cross-linker was later added as per the amount given in Table 1. Subsequently, the temperature was raised to $90^{\circ} \mathrm{C}-95^{\circ} \mathrm{C}$ keeping the constant stirring 2 hrs. After completion of cross-linking the solution was brought to room temperature for further analysis.

\subsection{Casting of Films}

A bar applicator was used for casting films of $1000 \mu \mathrm{m}$. The films were then kept 
Table 1. Preparation of various adhesive compositions with glyoxal.

\begin{tabular}{cccccc}
\hline & Blends & PVA & Starch & Glyoxal & Water \\
\hline Formulation 1 & PVA/S-07 & 25 & 5 & 0 & 70 \\
& PVA/S-GLY.01 & 25 & 5 & 0.5 & 70 \\
& PVA/S-GLY.02 & 25 & 5 & 1.0 & 70 \\
Formulation 2 & PVA/S-GLY.03 & 25 & 5 & 1.5 & 70 \\
& PVA/S-08 & 20 & 10 & 0 & 70 \\
& PVA/S-GLY.04 & 20 & 10 & 0.5 & 70 \\
& PVA/S-GLY.05 & 20 & 10 & 1.0 & 70 \\
& PVA/S-GLY.06 & 20 & 10 & 1.5 & 70
\end{tabular}

at room temperature for curing for $24 \mathrm{hrs}$.

Formulation 1:

For formulation 1, the PVA/S blend was kept constant at 25/5 with composition of glyoxal varied from 0 to 1.5 (Table 1 ).

Formulation 2:

For formulation 1, the PVA/S blend was kept constant at 20/10 with composition of glyoxal varied from 0 to 1.5 (Table 1 ).

\section{Characterization and Testing}

\subsection{Viscosity}

A Brookfield DV1 Viscometer was used to measure the viscosities of the formulations 1 and 2 . All readings were taken at $30^{\circ} \mathrm{C}$.

\subsection{Fourier Transform Infra-Red Spectroscopy (FTIR)}

Infrared spectra of crosslinked PVA and starch blends were measured on a PerkinElmer FTIR spectrum 100 instrument. Thin films were made from crosslinked blends prior to analysis.

\subsection{Differential Scanning Calorimetry (DSC)}

A Perkin Elmer instrument Q100 DSC has been used for estimating the glass transition temperature $\left(\mathrm{T}_{\mathrm{g}}\right)$.

\subsection{Pencil Hardness Test}

Testing method employed to calculate pencil hardness was ASTM D 3363.

\subsection{Ultimate Stress of Films}

ATinus Olsen 5ST instrument was used for determining the ultimate stress of the films.

\subsection{Tensile Strength}

A Tinus Olsen H25KT instrument has been used for calculating the tensile 
strength. Two pieces of steamed beech wood were taken for determining the tensile strength. The adhesive was applied on one end $(2.5 \mathrm{~cm} \times 2.5 \mathrm{~cm})$ of the two pieces and was held together for 2 and $24 \mathrm{hrs}$ at room temperature. The cured wood samples were then tested using a controlled speed of $10 \mathrm{~mm} / \mathrm{min}$ to obtain the tensile strength values.

\section{Results and Discussion}

The hydroxyl groups of PVA and starch react with glyoxal via formation of acetal bonds hence crosslinking could take place [25]. Since, the glyoxal at $90^{\circ} \mathrm{C}$ reacts with the hydroxyl groups, forming a between two inter-molecular chains for intra-molecular chains. The medium required for this reaction to occur is acidic, which is inherent in the solution. The cross-linking mechanism of PVA/S with glyoxal is given below in Figure 1. The results obtained by carrying out various tests are given in Table 2 (Formulation 1) and Table 3 (Formulation 2)

\subsection{Viscosity}

The glyoxal acts as a cross-linker for PVA/S, which has led to subsequent viscosity
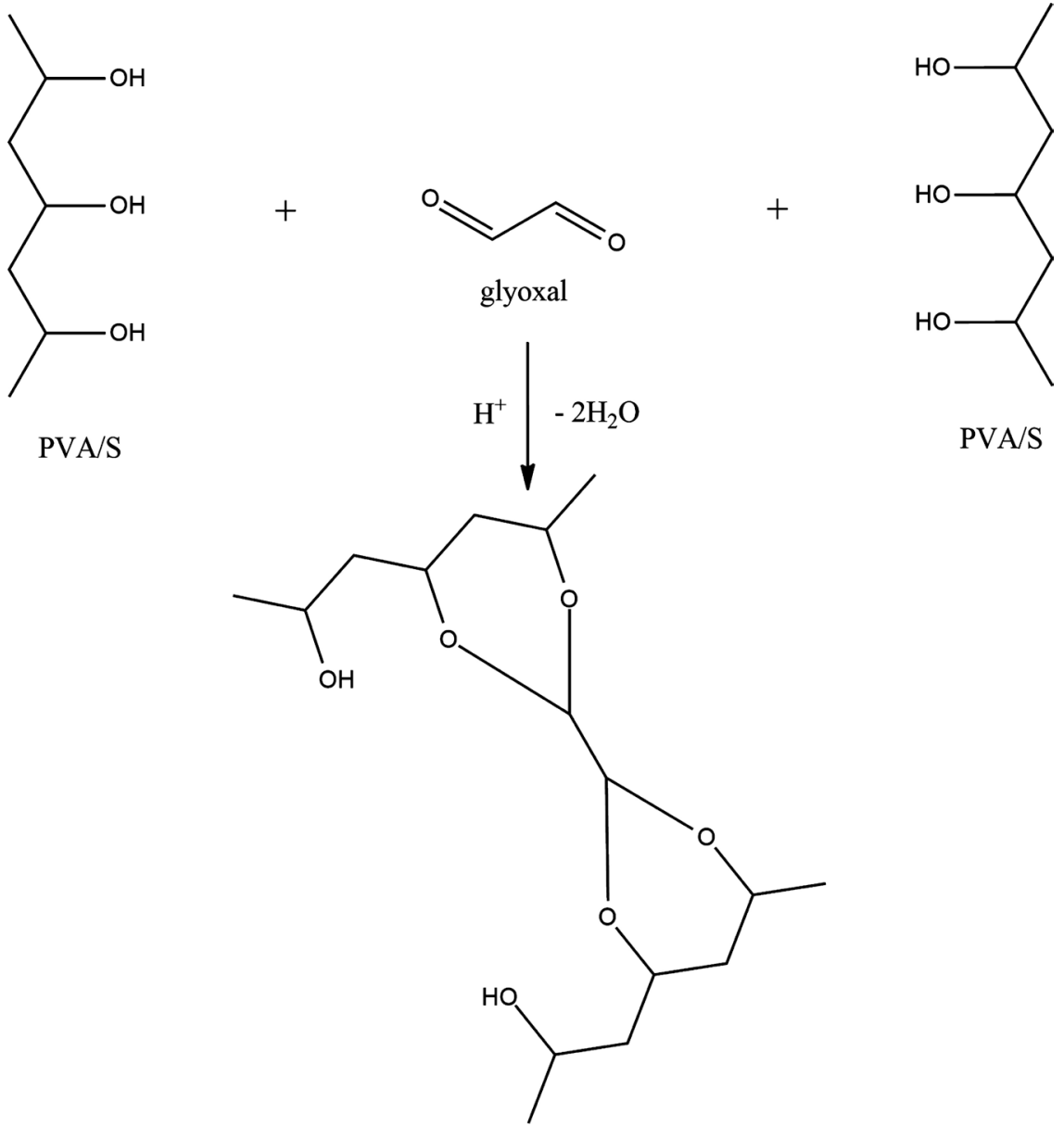

PVA/S crosslinked with glyoxal

Figure 1. Crosslinking of mechanism of PVA/S with glyoxal. 
Table 2. Results obtained by carrying out various tests for Formulation 1.

\begin{tabular}{ccccccc}
\hline & $\begin{array}{c}\text { Viscosity } \\
\text { (poise) }\end{array}$ & $\begin{array}{c}\text { Ultimate } \\
\text { Stress }\end{array}$ & $\begin{array}{c}\text { Tg } \\
\left({ }^{\circ} \mathrm{C}\right)\end{array}$ & $\begin{array}{c}\text { Pencil } \\
\text { hardness }\end{array}$ & \multicolumn{2}{c}{ Tensile strength (Kg/sq.in.) } \\
\cline { 7 - 7 } \cline { 6 - 7 } PVA/S-07 & 46 & 7.6 & 65 & $\mathrm{H}$ & 7 & 24 hrs \\
\hline PVA/S-GLY.01 & 65 & 8.9 & 67 & $6 \mathrm{H}$ & 7.1 & 11.2 \\
PVA/S-GLY.02 & 71 & 9.7 & 70 & $6 \mathrm{H}$ & 8.4 & 11.4 \\
PVA/S-GLY.03 & 85 & 14.7 & 72 & $7 \mathrm{~B}$ & 8.5 & 12.8 \\
\hline
\end{tabular}

Table 3. Results obtained by carrying out various tests for Formulation 2.

\begin{tabular}{ccccccc}
\hline & $\begin{array}{c}\text { Viscosity } \\
\text { (poise) }\end{array}$ & $\begin{array}{c}\text { Ultimate } \\
\text { Stress }\end{array}$ & $\begin{array}{c}\mathrm{Tg} \\
\left({ }^{\circ} \mathrm{C}\right)\end{array}$ & $\begin{array}{c}\text { Pencil } \\
\text { hardness }\end{array}$ & $\begin{array}{c}\text { Tensile strength (Kg/sq.in.) } \\
\text { 2 hrs }\end{array}$ & $\mathbf{2 4}$ hrs \\
PVA/S-08 & 55 & 7.9 & 69 & $2 \mathrm{H}$ & 7.2 & 9.3 \\
PVA/S-GLY.04 & 65 & 9.9 & 70 & $5 \mathrm{H}$ & 7.8 & 10.3 \\
PVA/S-GLY.05 & 73 & 10.8 & 72 & $7 \mathrm{H}$ & 8.2 & 12.9 \\
PVA/S-GLY.06 & 93 & 16.4 & 73 & $7 \mathrm{H}$ & 9.9 & 14 \\
\hline
\end{tabular}
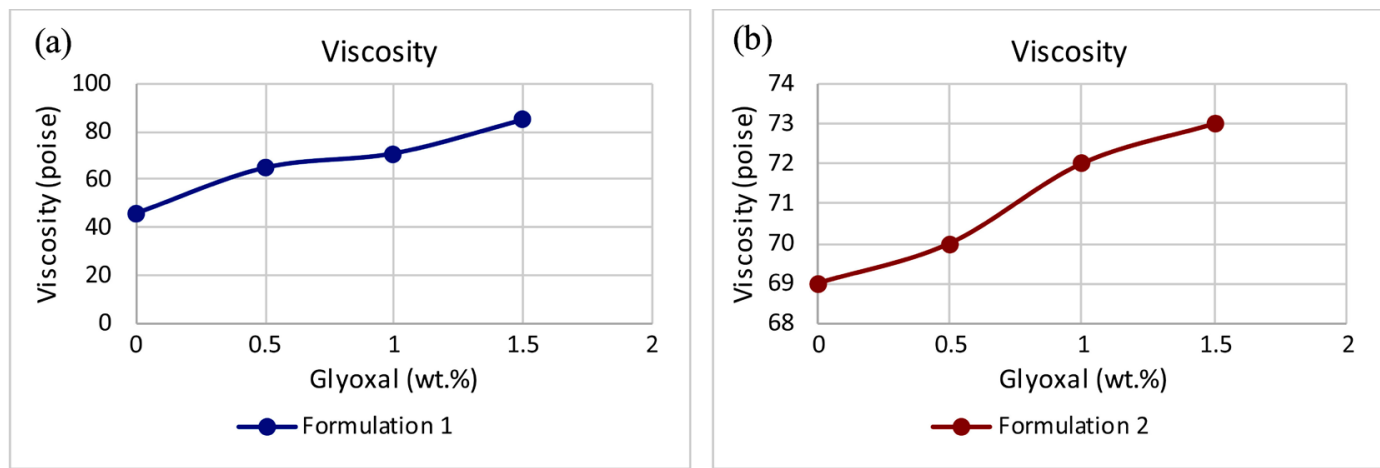

Figure 2. Viscosity at increasing concentration of glyoxal given by (a) Formulation 1 and (b) Formulation 2.

change as shown in Figure 2.

The effect of cross-linking between the hydroxyl groups of PVA/S is evident in Figure 2. The glyoxal has reacted with the hydroxyl groups and thus forming a cross-link. This cross-link increases the chain length of the PVA and S, thus the increase in viscosity. Since, the longer chain length increases the chances of entanglement, it has led to increase in viscosity as evident in Figure 2. Although, while comparing the formulation 1 and formulation 2 values, we get a much greater viscosity in formulation 2 . This is due to presence of hydrolyzed starch which has contributed to increase in viscosity.

\subsection{Fourier Transform Infra-Red Spectroscopy (FTIR)}

As, the concentration of cross-linker is increased, there is a movement of curve towards the lower wave number. This is observed since the cross-linker reduces the distance between chains by bridging between them, this bridging leads to lower H-bonding in the adhesive. The effect of decreased H-bonding can be seen 
in Figure 3 as the curve shifts towards lower wavenumber. Additionally, the increase in starch content also contributes to decrease in H-bonding (shown in Figure 3).

\subsection{Differential Scanning Calorimetry (DSC)}

The glyoxal acts as a cross-linker for PVA/S, which has led to subsequent glass transition temperature change as shown in Figure 4.

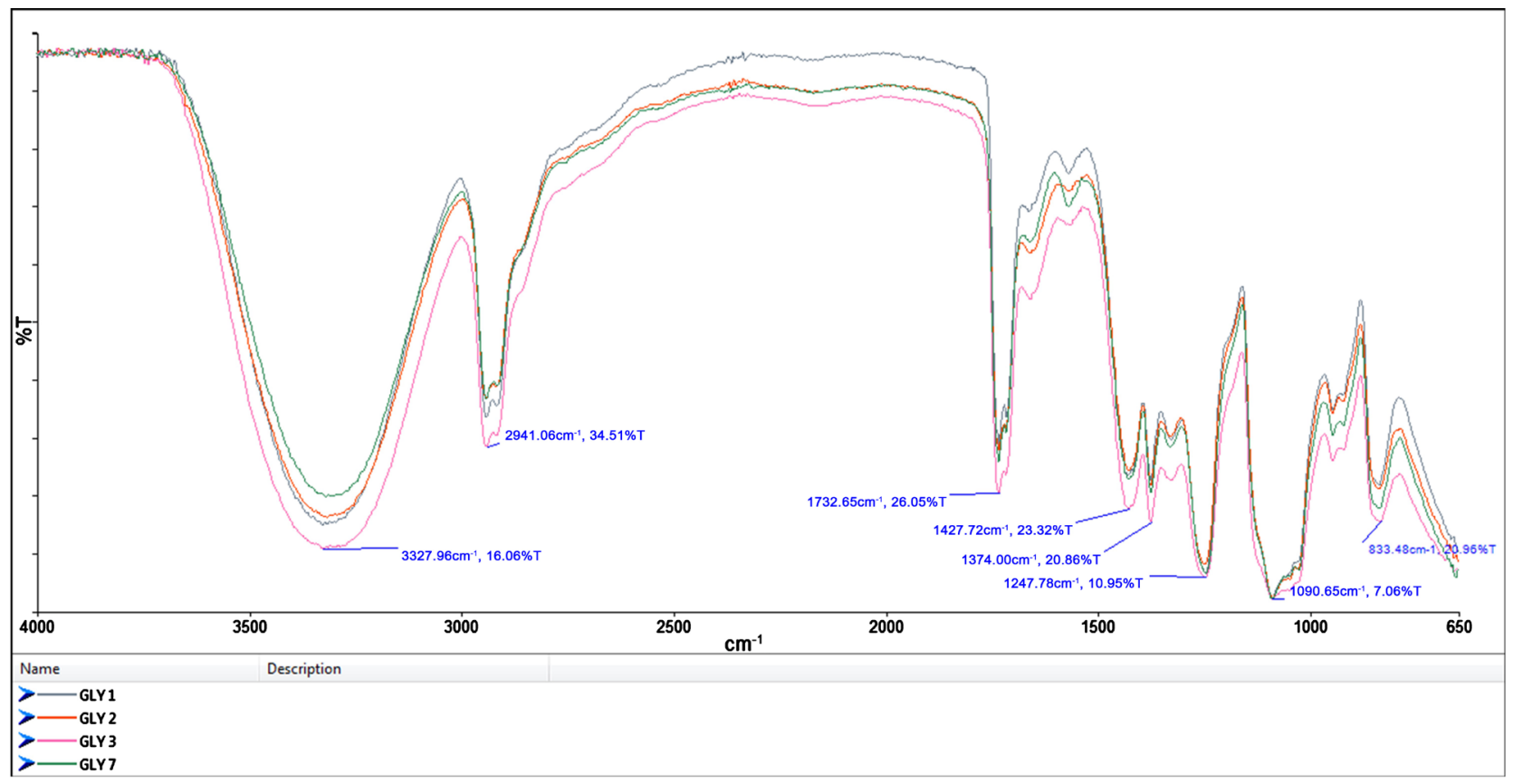

(a)

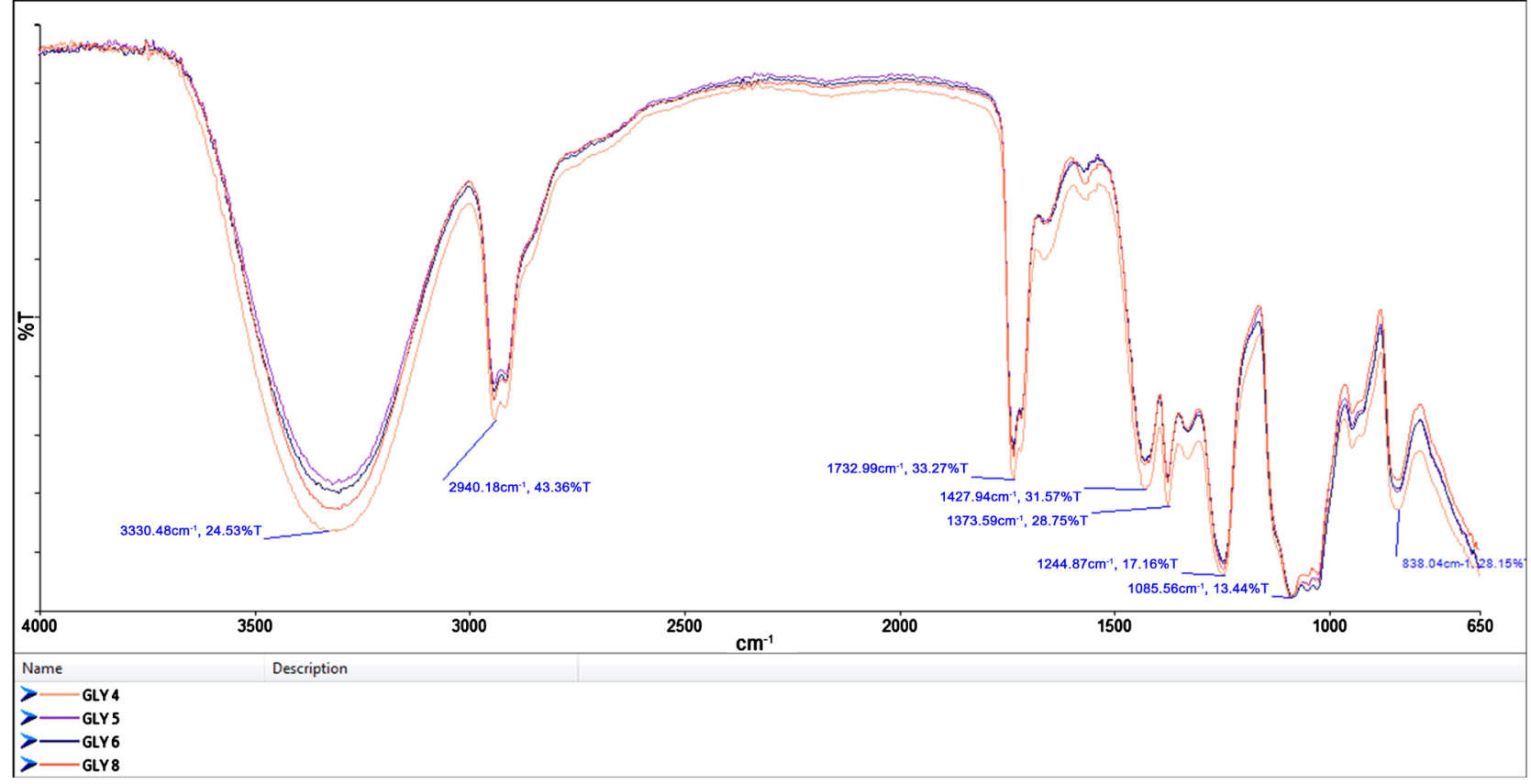

(b)

Figure 3. FTIR curves for (a) Formulation 1 and (b) Formulation 2. 
The effect of cross-linking between the hydroxyl groups of PVA/S is evident in Figure 4. The glyoxal has reacted with the hydroxyl groups and thus forming a cross-link. This cross-link increases the chain length of the PVA and S, thus the increase in glass transition temperature. As evident from the FTIR curves, there is a decrease in H-bonding of the adhesive with subsequent increase in cross-linker. The similar trend is observed for $\mathrm{Tg}$, there is an increase in $\mathrm{Tg}$ with increase in concentration of cross-linker. In comparing formulation 1 and formulation 2, there is slightly higher Tg for formulation 2 due to hydrolysis of starch.

\subsection{Pencil Hardness of Film}

Pencil hardness is a property dependent on the flexibility of the polymeric chains. The flexible chains of PVA are replaced partially by starch (which contains large 6 membered rings). The presence of rings in starch has contributed to increase in hardness of the formulations 2. Better cohesion in blends has also contributed to increase in hardness (as seen in Table 4). Both the formulations show a large difference in hardness with and without cross-linker. The cross-linking has clearly enhanced the hardness of the blends.

\subsection{Tensile Shear Strength}

The glyoxal acts as a cross-linker for PVA/S, which has led to subsequent tensile strength change as shown in Figure 5.

Table 4. Values of pencil hardness by cross-linking with glyoxal.

\begin{tabular}{cccc}
\hline \multicolumn{2}{c}{ Formulation 1 } & \multicolumn{2}{c}{ Formulation 2 } \\
\hline Blends & Pencil Hardness & Blends & Pencil Hardness \\
PVA/S-07 & $\mathrm{H}$ & PVA/S-08 & $2 \mathrm{H}$ \\
PVA/S-GLY.01 & $6 \mathrm{H}$ & PVA/S-GLY.04 & $5 \mathrm{H}$ \\
PVA/S-GLY.02 & $6 \mathrm{H}$ & PVA/S-GLY.05 & $7 \mathrm{H}$ \\
PVA/S-GLY.03 & $7 \mathrm{H}$ & PVA/S-GLY.06 & $7 \mathrm{H}$ \\
\hline
\end{tabular}
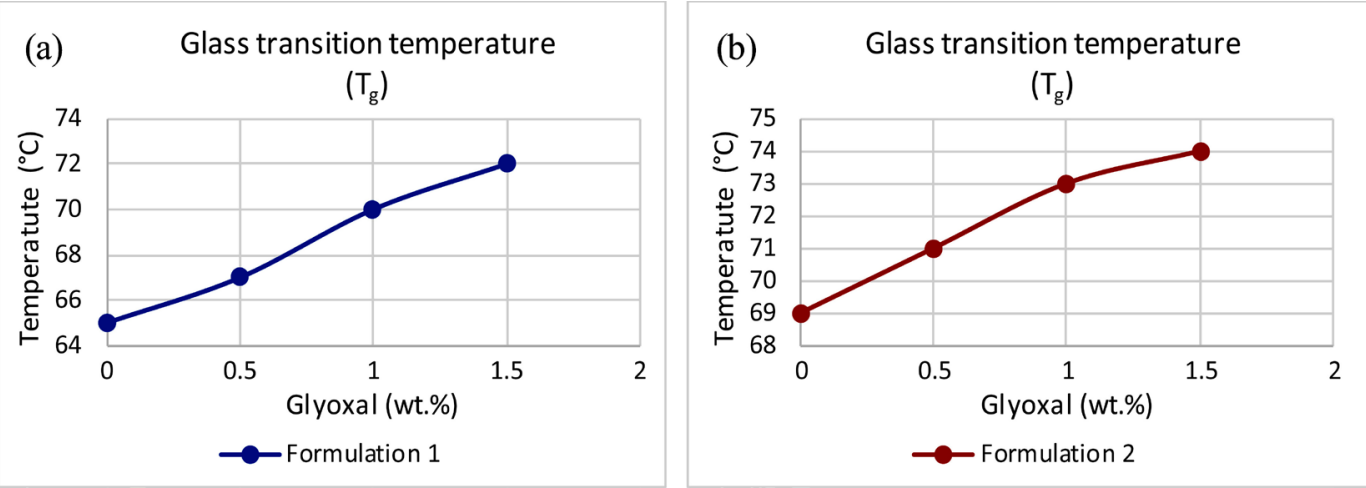

Figure 4. Glass transition temperature $\left(\mathrm{T}_{\mathrm{g}}\right)$ at increasing concentration of glyoxal given by (a) Formulation 1 and (b) Formulation 2. 
As seen in the previous sections, there is an increase in viscosity, glass transition temperature and pencil hardness of the blends. The tensile strength shows a similar trend as there is decrease in free volume between the chains, there is an increase in number of hydroxyl groups at the surface, as the hydroxyl groups become abundant on the surface there is an increase in tensile strength. Since, more cross-linker causes this decrease in free volume more rapidly, the tensile strength is increased subsequently (Figure 5(a) and Figure 5(b)). The cohesion between chains has also increased which further reduces the chances of tensile failure.

\subsection{Ultimate Stress of Films}

The cross-linking of glyoxal has decreased the mobility of the polymer chains. This has led to increase in stress bearing capacity of the chains. Thereby, increasing the stress required to break the blends. Also while comparing the formulation 1 and formulation 2, the larger number of six membered ring in starch help in increasing the stress (as seen from Table 5).

\section{Conclusion}

The cross-linking of PVA/S blends has efficiently increased thermal and mechanical properties. There is an increase in cohesion and decrease in H-bonding which has contributed majorly to increase in viscosity. Mechanical properties such as tensile strength, ultimate stress and pencil hardness have also shown

Table 5. Values of ultimate stress by cross-linking with glyoxal.

\begin{tabular}{cccc}
\hline \multicolumn{2}{c}{ Formulation 1 } & \multicolumn{2}{c}{ Formulation 2 } \\
\hline Blends & Ultimate stress & Blends & Ultimate stress \\
PVA/S-07 & 7.6 & PVA/S-08 & 7.9 \\
PVA/S-GLY.01 & 8.9 & PVA/S-GLY.04 & 9.9 \\
PVA/S-GLY.02 & 9.7 & PVA/S-GLY.05 & 10.8 \\
PVA/S-GLY.03 & 14.7 & PVA/S-GLY.06 & 16.4 \\
\hline
\end{tabular}
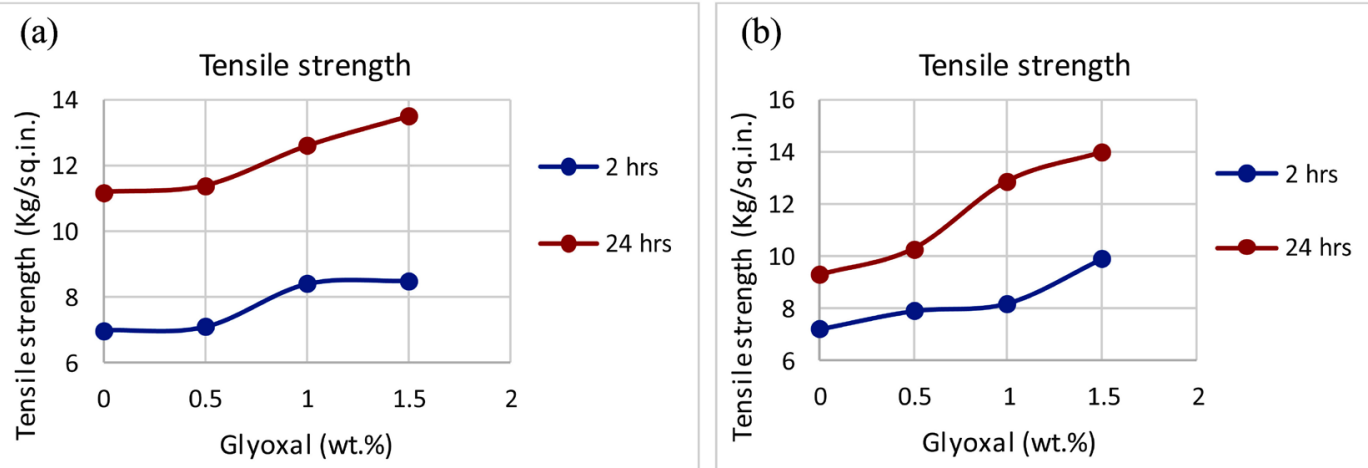

Figure 5. Tensile shear strength with increasing concentration of glyoxal after 2 hrs and 24 hrs of (a) Formulation 1 and (b) Formulation 2. 
enhancing effect due to cross-linking. There is a shift in the glass transition temperature which supports the cross-linking mechanism. FTIR proves the presence of H-bonding which has effected its various thermal and mechanical properties. The presence of more starch content is found to increase the cross-linking due to easy accessibility for cross-linker to attack hydroxyl groups. Additionally, an increase in ratio of starch to PVA in a blend with constant concentration of glyoxal resulted in increase in the mechanical and thermal properties.

\section{Conflicts of Interest}

The authors declare no conflicts of interest regarding the publication of this paper.

\section{References}

[1] Bemiller, J. and Whistler, R. (2009) Starch: Chemistry and Technology. 3rd Edition, Academy Press, Cambridge, 310-315.

[2] Wang, Z.J., Gu, Z.B., Li, Z.F., Hong, Y. and Cheng, L. (2013) Effects of Urea on Freeze-Thaw Stability of Starch-Based Wood Adhesive. Carbohydrate Polymers, 95, 397-403. https://doi.org/10.1016/j.carbpol.2013.02.009

[3] Imam, S.H., Gordon, S.H., Mao, L. and Chen, L. (2001) Environmentally Friendly Wood Adhesive from a Renewable Plant Polymer: Characteristics and Optimization. Polymer Degradation and Stability, 73, 529-533. https://doi.org/10.1016/S0141-3910(01)00114-8

[4] Kaewtatip, K. and Tanrattanakul, V. (2008) Preparation of Cassava Starch Grafted with Polystyrene by Suspension Polymerization. Carbohydrate Polymers, 73, 647-655. https://doi.org/10.1016/j.carbpol.2008.01.006

[5] Sanjiv Kasbe, P., Kumar, N. and Manik, G. (2017) A Molecular Simulation Analysis of Influence of Lignosulphonate Addition on Properties of Modified 2-Ethyl Hexyl Acrylate/Methyl Methacrylate/Acrylic Acid Based Pressure Sensitive Adhesive. International Journal of Adhesion and Adhesives, 78, 45-54. https://doi.org/10.1016/j.ijadhadh.2017.06.014

[6] Qu, B., Li, H. and Niu, Y. (2013) Graft Copolymerization of Poly(vinyl acetate) onto Starch Using $\mathrm{KMnO}_{4}-\mathrm{H}_{2} \mathrm{SO}_{4}$ Redox System. Journal of Polymer Engineering, 33, 521-526. https://doi.org/10.1515/polyeng-2013-0105

[7] Zhang, Y., Ding, L., Gu, J., Tan, H. and Zhu, L. (2015) Preparation and Properties of a Starch Based Wood Adhesive with High Bonding Strength and Water Resistance. Carbohydrate Polymers, 115, 32-37. https://doi.org/10.1016/j.carbpol.2014.08.063

[8] Conner, A.H., Lorenz, L.F. and River, B.H. (1989) Carbohydrate-Modified Phenol-Formaldehyde Resins Formulated at Neutral Conditions. ACS Symposium Series, 385, 355-369. https://doi.org/10.1021/bk-1989-0385.ch025

[9] Moubarik, A., Pizzi, A., Allal, A., Charrier, F. and Charrier, B. (2009) Cornstarch and Tannin in Phenol-Formaldehyde Resins for Plywood Production. Industrial Crops and Products, 30, 188-193. https://doi.org/10.1016/j.indcrop.2009.03.005

[10] Moubarik, A., Charrier, B., Allal, A., Charrier, F. and Pizzi, A. (2010) Development and Optimization of a New Formaldehyde-Free Cornstarch and Tannin Wood Adhesive. European Journal of Wood and Wood Products, 68, 167-177. https://doi.org/10.1007/s00107-009-0357-6 
[11] Amine, M., Nicolas, C., Thomas, P., Ahmed, A., Antonio, P. and Fatima, C. (2012) Shear Refinement of Formaldehyde-Free Corn Starch and Mimosa Tannin (Acacia mearnsii) Wood Adhesives. Journal of Adhesion Science and Technology, 25, 1701-1713. https://doi.org/10.1163/016942411X576176

[12] Tan, H., Zhang, Y. and Weng, X. (2011) Preparation of the Plywood Using Starch Based Adhesives Modified with Blocked Isocyanates. Procedia Engine, 15, 1171-1175. https://doi.org/10.1016/j.proeng.2011.08.216

[13] Karim, A.A., Norziah, M.H. and Seow, C.C. (2000) Methods for the Study of Starch Retrogradation. Food Chemistry, 71, 9-36. https://doi.org/10.1016/S0308-8146(00)00130-8

[14] Gadhave, R.V., Mahanwar, P.A. and Gadekar, P.T. (2018) Starch Stabilized Polyvinyl Acetate Emulsion: Review. Polymers from Renewable Resources, 9, 75-84. https://doi.org/10.1177/204124791800900203

[15] Li, Z., Wang, J., Li, C., Gu, Z., Cheng, L. and Hong, Y. (2015) Effects of Montmorillonite Addition on the Performance of Starch-Based Wood Adhesive. Carbohydrate Polymers, 115, 394-400. https://doi.org/10.1016/j.carbpol.2014.08.106

[16] Masci, G., Husu, I., Murtas, S., Piozzi, A. and Crescenzi, V. (2003) Physical Hydrogels of Poly(vinyl alcohol) with Different Syndiotacticity Prepared in the Presence of Lactosilated Chitosan Derivatives. Macromolecular Bioscience, 3, 455-461. https://doi.org/10.1002/mabi.200350017

[17] Othman, N., Azahari, N.A. and Ismail, H. (2011) Thermal Properties of Polyvinyl Alcohol (PVOH)/Corn Starch Blend Film. Malaysian Polymer Journal, 6, 147-154.

[18] Klenina, O.V., Klenin, V.I. and Frenkel, S.Ya. (1970) Formation and Breakdown of Supermolecular Order in Aqueous PVA Solutions. Polymer Science USSR, 12, 1448-1461. https://doi.org/10.1016/0032-3950(70)90077-8

[19] Stauffer, S.R. and Peppas, N.A. (1992) Poly(vinyl alcohol) Hydrogels Prepared by Freezing-Thawing Cyclic Processing. Polymer, 33, 3932-3936. https://doi.org/10.1016/0032-3861(92)90385-A

[20] Gadhave, R.V., Kasbe, P.S., Mahanwar, P.A. and Gadekar, P.T. (2018) To Study the Effect of Boric Acid Modification on Starch-Polyvinyl Alcohol Blend Wood Adhesive. Journal of the Indian Academy of Wood Science, 15, 190-198. https://doi.org/10.1007/s13196-018-0225-2

[21] Nambu, M. (1984) Freeze-Dried Poly(vinyl alcohol) Gel. US Patent No. 4,472,542.

[22] Othman, N., Azahari, N.A. and Ismail, H. (2011) Thermal Properties of Polyvinyl Alcohol (PVOH)/Corn Starch Blend Film. Malaysian Polymer Journal, 6, 147-154.

[23] Rahayu, L.B.H., Wulandari, I.O., Santjojo, D.H. and Sabarudin, A. (2018) Synthesis and Characterization of $\mathrm{Fe}_{3} \mathrm{O}_{4}$ Nanoparticles Using Polyvinyl Alcohol (PVA) as Capping Agent and Glyoxal (GA) as Crosslinker. IOP Conference Series: Materials Science and Engineering, 299, Article ID: 012062. https://doi.org/10.1088/1757-899X/299/1/012062

[24] Park, J.Y., Hwang, K.J., Yoon, S.D., Lee, J.H. and Lee, I.H. (2015) Influence of Glyoxal on Preparation of Poly(Vinyl Alcohol)/Poly(Acrylic Acid) Blend Film. Journal of Nanoscience and Nanotechnology, 15, 5955-5958. https://doi.org/10.1166/jnn.2015.10470

[25] Blanes, M., Gisbert, M.J., Marco, B., Bonet, M., Gisbert, J. and Balart, R. (2010) Influence of Glyoxal in the Physical Characterization of PVA Nanofibers. Textile Research Journal, 80, 1465-1472. https://doi.org/10.1177/0040517509357654

[26] Gahlawat, P., Sen, C. and Das, M. (2015) Effect of Molecular Weight of Polyvinyl Alcohol on Properties of Starch Film Cross-Linked with Glutaraldehyde. Journal of Agricultural Engineering and Food Technology, 2, 12-16. 